Archivum, LXXI, 2021, pp. 279-310

\title{
La generación gay del 27. Literatura homosexual en el debate de la Modernidad de principios de siglo $\mathrm{XX}^{*}$
}

\author{
José Martínez Rubio \\ Universitat de VALÈnCIA \\ jose.martinez-rubio@uv.es
}

Recibido: 25/03/2021

Aceptado: 07/07/2021

\begin{abstract}
RESUMEN:
A comienzos del siglo XX se produjo un auge en las publicaciones populares espanolas de género erótico, en las cuales se comenzó a representar la homosexualidad como tema literario. En muchas novelas la homosexualidad se reflejaba como signo de libertad y como ejemplo de las nuevas formas de vida modernas. Bajo la influencia de Wilde o de Gide, autores como Álvaro Retana, Pedro Badanelli o Antonio Hoyos y Vinent, frívolos, modernistas o decadentistas, participaron en un debate que trascendió lo literario.
\end{abstract}

PALABRAS CLAVE: Literatura gay; modernismo; decadentismo; Generación del 27.

* Este trabajo se ha desarrollado en el marco del Proyecto de Investigación Emergente Memory Novels Lab: Laboratorio Digital de Novelas sobre Memoria Histórica Española, financiado por la Generalitat Valenciana (GV/2021/183) 
The gay Generation of '27. Homosexual literature in the debate of Modernity in the early 20th century

\begin{abstract}
:
At the beginning of the 20th century there was a boom in popular Spanish erotic publications, in which homosexuality was represented as a literary topic. In many novels homosexuality was reflected as a sign of freedom and as an example of the new modern ways of life. Under the influence of Wilde or Gide, authors such as Álvaro Retana, Pedro Badanelli or Antonio Hoyos y Vinent, frivolous, modernists or decadentists, participated in a debate beyond the literary.
\end{abstract}

KEYWORDS: Gay literature; modernism; decadentism; Generation of '27.

Él es como el fox-trot y como la morfina un producto que trajo la civilización. Saben a éter sus libros, a ajenjo, a cocaina; en ellos la sonrisa oculta el corazón...

(Antonio Campor)

\title{
Introducción
}

En el largo camino de la Modernidad nadie duda de la renovación estética que supuso el advenimiento de la llamada "generación del 27" para las letras hispánicas. La liberación del verso, la capacidad introspectiva del yo poético, el alejamiento de formas convencionales y de la poesía retórica, la preeminencia del intimismo frente al sentimentalismo, la búsqueda de nuevos modos de expresión en línea con las vanguardias históricas, la apuesta por el esteticismo que llevaba practicándose (al menos) desde el periodo modernista con Juan Ramón Jiménez y Rubén Darío, sitúan a esta "generación" (García de la Concha, 1998) como epítome de toda una reflexión literaria y estética que podría converger en algunas de estas cuestiones: cómo expresar la subjetividad del individuo en un mundo moderno, intrínsecamente cambiante, autodestructivo y fecundo al mismo tiempo; qué espacio ocupa la intimidad en un mundo tecnológicamente avanzado; qué papel reservan los tiempos al arte y a la reflexión humana. 
$\mathrm{Al}$ calor de esa generación brillante, en las últimas décadas hemos vivido un proceso de recuperación de otras formas literarias convergentes en el tiempo y en los planteamientos propios de la Modernidad. Es el caso de "la otra generación del 27", membrete que acuñó uno de sus participantes, José López Rubio, en su discurso de ingreso en la Real Academia Española en 1983 (Romera Castillo, 1995, 241). Siguiendo a Pedro Laín Entralgo, López Rubio destacaba la generación de dramaturgos e ilustradores que desde los años veinte habían sido "renovadores -los creadores más bien- del humor contemporáneo" (López Rubio, 2003, 42): Miguel Mihura, Jardiel Poncela, Edgar Neville, José López Rubio, K-HITO o Tono, entre otros.

También el 27 fue el resorte para recuperar otra generación olvidada, "Las sin sombrero" (Balló, 2016): mujeres pintoras, escritoras, ilustradoras, filósofas o escultoras que, en diálogo con los del 27, produjeron y crearon piezas artísticas de gran valor, al tiempo que fueron capaces de reivindicar y visibilizar el papel femenino en la cultura española de entreguerras, así como en la política y en todos los planos de la esfera pública ${ }^{1}$. El reciente proyecto crossmedia (Balló, Tània; Jiménez, Manuel; Torre, Serrana, 2016) recupera figuras como las de María Teresa León, Ernestina de Champourcín, Rosa Chacel, Concha Méndez, Josefina de la Torre, María Zambrano, Maruja Mallo o Marga Gil Roësset²

No es mi intención acuñar una nueva generación del 27 para la historia de la literatura, como se ha venido haciendo con total legitimidad en los últimos años en los casos mencionados. Pero si bien me parece saludable la recuperación y reivindicación de dramaturgos, humoristas o mujeres artistas e intelectuales para completar el paisaje de esa Modernidad que avanza con paso firme en la cultura española de los años veinte y treinta, tam-

1 Fruto de estas reivindicaciones feministas, en 1931 la Constitución Española de la II República aprobó el voto universal femenino.

2 Para una mayor profundidad, remito al libro de Balló (2016), al proyecto crossmedia https://www.lassinsombrero.com/ y a los tres documentales dedicados a esta generación: Las sin sombrero, Ocultas e impecables y El exilio. 
bién me parece legítimo recuperar las voces que plantean por primera vez los conflictos derivados de una condición sexual no heteronormativa como tema literario sin voluntad censora, los discursos artísticos que discuten con los discursos científicos o religiosos sobre la normalidad o anormalidad de determinadas subjetividades eróticas, y sobre la moralidad o inmoralidad de las personas homosexuales.

Si los movimientos de liberación homosexual irrumpieron con fuerza en los años sesenta y setenta del siglo XX para reclamar la despenalización y despatologización de la homosexualidad, así como una normalización y aceptación de las sexualidades no normativas en la esfera pública, y entendemos este combate en el contexto de lucha por los derechos civiles de las democracias occidentales, es justo destacar a toda esa generación de escritores que, desde diferentes posiciones políticas y desde un activismo principalmente literario, visibilizaron el "problema" homosexual en publicaciones de grandes tiradas desde principios de siglo $X X$, los nuevos modos de vida en las ciudades, los nuevos tipos de relaciones afectivas y homofílicas entre hombres y dieron cauce a la expresión (no siempre amable) de una sexualidad disidente, gozosa o dolorosa, proscrita o relegada a ambientes festivos, cuando no sórdidos. Es justo pues volver sobre aquellos que, en definitiva, empezaron a hablar de la homosexualidad como rasgo de una colectividad en diálogo convulso con la Modernidad.

Mi interés en este trabajo es el de destacar algunas obras de esta generación ${ }^{3}$ que trataron de visibilizar diferentes aspectos

3 A sabiendas de la complejidad y la problemática de las clasificaciones generacionales tomamos, pues, el término "generación" en un sentido laxo. Los de esta "generación" son escritores que, en el primer tercio de siglo XX y en especial en las décadas de los 10 y 20, producen un tipo de literatura que propone la vivencia de la homosexualidad como tema literario. Por supuesto, la referencia a la generación del 27, en tanto que emblemática de la modernidad literaria de la literatura española, pretende asociar a la "generación gay" a un debate sobre las transformaciones estéticas, culturales, sociales y políticas que está produciéndose en España en el primer tercio de siglo, y que se verá cortado de manera abrupta durante décadas por la instauración de una dictadura como la franquista, esencialmente antimoderna. 
de la cultura gay, o que combatieron la homofobia del país mediante estrategias en ocasiones valientes, en ocasiones ambiguas. A partir de estos textos, además, se pueden rastrear los modos de vivir, las relaciones afectivas, las prácticas y los lugares de encuentro de las primeras comunidades ${ }^{4}$ homosexuales en España.

\section{Literatura erótica y relajación de costumbres: la homosexua-} lidad como límite de la Modernidad (1900-1930)

Alberto Mira afirma que el discurso homosexual en España comienza a desarrollarse fuera del campo médico y religioso tras la Primera Guerra Mundial, momento en que situaríamos el nacimiento de una "cultura gay" relacionada intrínsecamente "con la llegada de la Modernidad" (Mira, 2007, 29). A pesar de ello, la regeneración española, deseada por los noventayochistas y muchos de los intelectuales de entresiglos, tanto conservadores como progresistas en términos políticos, centraría su preocupación en el desarrollo económico, científico y educativo de España, el avance de la cultura, la industrialización del país y la apertura del Estado al concierto internacional, dominado por el multilateralismo a partir de 1919, como una nueva manera de situarse en el plano de las relaciones internacionales una vez certificado (o ratificado) el fin del Imperio Español de ultramar en 1898, agravado por la penosa gestión administrativa de las colonias en África y por las humillantes derrotas militares de primer tercio de siglo. La cuestión de la sexualidad será clave en ese nuevo aperturismo de principios de siglo XX: mientras que los intelectuales y escritores progresistas defenderán la libertad de expresión en las obras artísticas, aquellos de signo conservador repetirán las consabidas acusaciones sobre la enfermedad social, la degeneración de las costumbres y el atentado contra la moral pública. El debate sobre la sexualidad reproduce las mismas posiciones articuladas en el nacimiento de la Modernidad: defensa

4 Entiendo por "comunidad" la conformación de un grupo reconocido como tal a partir de una identidad "gay" y que, de algún modo, se proyecta públicamente en la sociedad moderna. 
de la razón, del derecho de expresión y del avance social, frente a defensa de la moralidad y de las costumbres tradicionales. No debemos soslayar que en el ámbito científico, principalmente desde la medicina, la psiquiatría o la sexología, se discute su consideración patológica e inmoral desde la segunda mitad de siglo XIX en Alemania y Francia, con sus consecuentes desarrollos legislativos represores de la homosexualidad, pero este debate llegará a España mucho más tarde, coincidiendo con las manifestaciones literarias que observamos en este trabajo (Vázquez García, 2001).

Signo de esta modernidad imparable, sumamente controvertida, es la aparición con fuerza del fenómeno literario de la novela erótica. El erotismo se distribuyó de manera masiva gracias a la literatura, la fotografía, el dibujo y el cine, interesando con gusto y placer incluso al propio rey Alfonso XIII, quien contaba en palacio con una sala de proyecciones personal y llegó a producir, bajo el elocuente sello Royal Films, al menos tres películas eróticas: El confesor, Consultorio de señoras y El ministro (Barea y otros, 2001). La literatura erótica alcanzó niveles de difusión altísimos gracias a las ediciones populares, que habían nacido para el gran público lector fraguado en la Modernidad del siglo XIX. Arranca de modo significativo en los años ochenta del siglo XIX y alcanza su plenitud en los años veinte y treinta del XX (Guereña, 2000; López Ruiz, 2001; Huertas Vázquez, 2015), momento en el que empieza a declinar debido a la repetición de temas y formas y al hartazgo del público (Villena, 1992, 322; Heuer, 2000, 644). Las publicaciones de quiosco, periódicas o incluso clandestinas (Guereña, 2012), la aparición de bibliotecas, editoriales y colecciones especializadas o la entronización de determinados autores (Felipe Trigo, Antonio de Hoyos y Vinent, José Francés, Eduardo Zamacois, Joaquín Belda, "El caballero audaz", seudónimo de José María Carretero Novillo, Álvaro Retana etc.) revisten un gran interés para el estudio de la literatura de principios de siglo y sus circuitos de producción y difusión, pero también despiertan un gran interés sociológico: a la luz de tales textos, 
podemos preguntarnos qué sociedad estaban gestando los nuevos tiempos modernos, qué reclamos de libertad demandaban las nuevas generaciones contra el pensamiento tradicional y autoritario, qué reacciones despertaban tales exhibiciones de descaro y hedonismo. Tal fue el impacto en la sociedad española de la literatura erótica, galante, frívola o pornográfica ${ }^{5}$, que uno de sus máximos exponentes, Álvaro Retana, llegó a teorizar en 1931 sobre este tipo de literatura en un ensayo de crítica literaria titulado La ola verde (Fortuny, 1931). Por supuesto, este género no fue ajeno a los distintos vaivenes de la historia, desde la permisividad liberal, a la represión de la dictadura de Primo de Rivera o a los aires de libertad de la II República, periodo en el cual el público ya había dado la espalda al género. Así pues, la sexualidad fue el catalizador en el que se enfrentaban la libertad y el placer con la censura y el escándalo, los anhelos de voluptuosidad frente a la salvaguarda de la moral pública. La aparición de El cuento semanal, y de su "generación" literaria ${ }^{6}$ (en opinión de Alberto Insúa, 2003, 145-46), de Los contemporáneos, La novela semanal, La novela de hoy (García Martínez, 2012), El libro popular, La novela corta, La novela del sábado, El cuento nuevo, La novela de noche, La novela de amor, La novela de bolsillo o La novela mundial, publicaciones todas ellas de gran tirada, a bajo precio y de corte popular, por donde se saciaban y promovían los nuevos gustos literarios y sexuales de la sociedad, coincidía con la aparición de asociaciones e instituciones que pretendían velar por la moral pública: Asociación de Padres de Familia de Cataluña (Barcelona, 1895) o la Liga contra la Pornografía (Madrid, 1912) (Guereña, 2000).

La literatura erótica fue considerada intrínsecamente "moderna" debido a su influencia extranjera (preferentemente fran-

5 Tomo tales adjetivos como referirme a un mismo tipo de literatura, recogiendo así la terminología de la época y de la crítica actual para indicar un tipo de novelas populares, breves y de temas o tonos sexuales.

6 Alberto Insúa dedica todo un artículo a "La generación de El cuento semanal", publicación en la que escribirán Emilia Pardo Bazán, Benito Pérez Galdós, Pío Baroja o Gabriel Miró, entre muchos otros. Cfr. Memorias (2003). 
cesa) y a que se entendía como la expresión de un nuevo tiempo de costumbres relajadas y aperturismo general; el erotismo era "un camino de educación, de liberación y de progreso" (Villena, 1992, 319). No menos "moderna" fue la consideración preclara de la corrupción de los tiempos, renovando esa contradicción de la Modernidad que describía Berman (2008): el proceso de cambio cultural alienta tanto los deseos de transformación en parte de la sociedad, como los lamentos por un pasado idealizado en otra. No obstante, el erotismo no daba cabida a todos por igual. Esta ola frívola no alcanzó a aceptar la homosexualidad con el mismo goce, e inscribirla en el debate social con voluntad normalizadora. En opinión de Alberto Mira, la modernidad tenía como límite, no la sexualidad (que era vista como una influencia extranjera, moderna y abierta), sino la homosexualidad (vista como degeneración de tal influencia): "Homo y hetero no son, en absoluto, dos posibilidades al mismo nivel. [...] 'Hetero' implica libertad, 'homo' se venía conceptualizando en términos de corrupción, locura, enfermedad, degeneración y criminalidad" (Mira, 2007, 80-81). La aversión hacia la homosexualidad, por parte de posiciones tanto conservadoras como liberales, estaba fuertemente arraigada en la sociedad española de principios de siglo, y era especialmente elocuente en las manifestaciones de regeneracionistas como Pío Baroja, Carmen de Burgos ${ }^{7}$, Rafael Cansinos Assens, Ramiro de Maeztu o Miguel de Unamuno (Heuer, 2000, 644; Mira, 2007, 88-89). De este modo, toda cultura gay que pudiera nacer al calor de la Modernidad debía estar dispuesta bien a luchar contra el pensamiento moderno y antimoderno, conservador o progresista, sabiéndose excluido del relato general de la Modernidad, bien a disimularse deliberadamente en la ambigüedad política.

7 El caso de Carmen de Burgos debe tomarse con precaución. Feminista en sus planteamientos, en El veneno del arte (1910) aborda la homosexualidad como una crítica hacia los círculos modernistas y decadentistas que frecuentaba (Mira, 2007: 89). No obstante, en Ella y ellos o ellos y ellas (1917) recrea el mundo de la frivolidad y destaca la libertad de las identidades no heteronormativas. 
Las novelas eróticas populares fueron permeables a los modelos literarios provenientes del resto de Europa. La historia cultural coincide en señalar el proceso contra Oscar Wilde como el inicio de las articulaciones de las identidades homosexuales en toda Europa. La visibilización de su condición gay, así como el juicio y condena a trabajos forzados por "conducta indecente" junto a su amante Lord Alfred Douglas, produjeron una repercusión en todo el continente que fue interpretada, en palabras de Alberto Mira, como "el fin de la inocencia" para las sociedades modernas (Mira, 2007, 35). Aun sin haber sido la primera persona en declarar su homosexualidad, ni mucho menos la primera víctima de una cultura y un Estado homófobos en su esencia y represores en sus prácticas, Wilde se erige como el primer mártir gay de la Modernidad. En España se lee a Wilde ${ }^{8}$ junto a Marcel Proust, el Conde de Lautréamont o el poeta Walt Whitman' ${ }^{9}$ inspiradores de toda la generación de escritores eróticos que llevarán el amor homosexual a las páginas de sus libros. Si la sombra de Wilde es alargada, no menos imponente será la de André Gide, cuya

8 Según la Biblioteca Nacional de España, El retrato de Dorian Gray fue publicado por primera vez en nuestro país precisamente en 1918 (Biblioteca Nueva; Publicaciones Atenea), reeditado posteriormente en 1929, y con ediciones de Clarasó, Cosmópolis y Zoila Aseasibar en 1930, con edición en catalán en la editorial Proa también en 1930, e incluso con una adaptación teatral en cuatro actos firmada por Remón Agustín en 1935. Años antes habían salido en catalán: Noveletes (Biblioteca de El Poble Català, 1906) y Salomé (Fidel Giró, 1908); en español: La casa de las granadas (Imprenta Hijos de Gómez Fuentenebro, 1909; Victoriano Suárez, 1910; Teatralia, 1910), La casa del juicio (Imprenta Helénica, 1911), Un marido ideal (E. Doménech, 1914; Publicaciones Atenea, 1917), Lady Windermere (E. Doménech, 1915), Salomé (La novela universal, 1917), La importancia de llamarse Ernesto (Publicaciones Atenea, 1917; Espasa, 1920; Espasa-Calpe, 1927), Una mujer sin importancia (Publicaciones Atenea, 1917), De profundis (Editorial América, 1920), así como antologías de obritas, piezas teatrales, frases célebres y textos ensayísticos (Biblioteca Nueva, 1918, 1920; Publicaciones Atenea, 1920; Editorial América, 1920). Pero junto a Wilde aparecen Jean Lorrain (El vicio errante, Sociedad de Ediciones Literarias y Artísticas, 1909; La feria de las pasiones, Rafael Caro Raggio, 1920; Viejas remozadas, G. Hernández y Galo Sáez, 1925; El señor de Phocas, s.n., 1925; El señor de Bougrelon y La dama turca, s.n., 1926; El burdel de Filiberto, Biblioteca Nueva, 1930).

9 En catalán: Fulles d'herba, Biblioteca Popular de l'Avenç, 1909; en español: Poemas, editor F. Sempere, 1912. 
reivindicativa novela Corydon (1924) será rápidamente traducida y publicada en España: Ediciones Oriente, 1929, edición española aumentada con dos retratos del autor; Editorial Argis, que en 1931 lanzó su tercera edición de la novela.

Junto a la publicación de estos autores "modernos" en España, es fundamental la recuperación del helenismo que se produce desde la estética. La Grecia clásica, la Antigüedad clásica en general, había sido motivo recurrente para la configuración de la Modernidad: como marco de perfección artística para el neoclasicismo, en términos de nostalgia o de paraíso perdido para los románticos (Berman, 2008). Sin embargo, una serie de acontecimientos acrecentaron el interés por Grecia y contribuyeron a configurar en el imaginario europeo la idea de una sociedad helénica amante de la belleza, cívica en su organización social, benigna y hedonista en sus costumbres, heroica en su historia, elevada en su pensamiento y excelsa en su creación artística. Fueron numerosos los contactos con el mundo antiguo a partir de la Modernidad: el descubrimiento de las ruinas de Olimpia y Delfos, de la cultura clásica que inspiró las creaciones de Percey B. Shelley o los estudios de Johan Winckelmann, la guerra de la independencia griega por la que luchó Lord Byron o el trazado del Grand Tour, el viaje iniciático para jóvenes aristócratas del norte y centro de Europa para conocer los orígenes del continente a orillas del Mediterráneo (Belmonte, 2015, 7-13). El triunfo del helenismo en las sociedades modernas desplaza al imaginario judeo-cristiano, organizador principal de la moral social, las relaciones humanas e incluso de la estética y la cultura tradicional española: el canto al amor sublime y pleno de Safo, a la amistad entre guerreros (Aquiles y Patroclo), el vínculo afectivo entre maestro y alumno (Sócrates y Alcibíades), la perfección canónica del desnudo masculino y femenino o la prevalencia de la belleza en términos platónicos.

Para la naciente cultura homosexual moderna, lo helénico concentrará la posibilidad, para autores y lectores, de recrearse en la belleza masculina y en la amistad masculina sin despertar 
demasiadas sospechas, es decir, camuflando el homoerotismo dentro del concepto general de belleza. Será recurrente la imagen del efebo, del adolescente vigoroso y lleno de vitalidad, que inmediatamente el discurso homófobo conectará a la pederastia ${ }^{10}$. El propio Oscar Wilde en El retrato de Dorian Gray (1890) plantea el deseo del propio protagonista de eternizar su juventud, y para ello realiza un pacto con el diablo. Thomas Mann en La muerte en Venecia (1912) reproduce la fascinación del escritor alemán Gustav von Aschenbach por el joven Tadzio, cuya belleza adolescente lo mantiene atado irremediablemente a una ciudad en la que se declara una epidemia de cólera; la decisión del intelectual será la permanencia en el lugar de la belleza, la renuncia a escapar y a resignarse a vivir lejos de Tadzio, aun siendo alcanzado por la muerte en las playas del Lido de Venecia. Stefan Zweig publica Confusión de sentimientos (1926), en la que narra la amistad y la admiración entre un alumno, Roland, y su profesor de literatura inglesa en una universidad de provincias del centro de Europa, los desplantes y cambios de humor del maestro, la angustia del discípulo ante su desaparición y su alejamiento, las dudas sobre sus sentimientos ambiguos y, finalmente, la confesión del profesor: el amor por el alumno, la desesperación por no poder completar la cercanía de las almas con la proximidad de los cuerpos y las escapadas a Berlín en busca de sexo clandestino en los bares de la gran capital ${ }^{11}$. Las descripciones efebofílicas, las referencias helénicas y el rescate de temas como la amistad y el amor sublime, o la relación maestro-alumno, son vertebrales en estas producciones de principios de siglo $\mathrm{XX}$, y ofrecen un modelo estético y afectivo incuestionable en la cultura occidental, a partir del cual plantear, de manera velada, los conflictos

10 'Pederastia', por cierto, fue un término muy problemático en el inicio de la lucha por la visibilidad gay y los derechos civiles en los años sesenta y setenta, llegando incluso a ser reivindicado por grupos homosexuales. Cfr. Huard (2014): pp. 226-230.

11 Incluso Marcel Proust dejaría inédita un relato abiertamente homosexual, Le mystérieux correspondant, publicado por primera vez en francés en 2019 (Éditions de Fallois) y en español en 2021 (Lumen) 
de la homosexualidad. Las fotografías de Wilhelm von Gloeden (1856-1931) en la Sicilia de principios de siglo eran buena muestra de ello: en esas imágenes, hace posar como pastores de la Arcadia feliz a los campesinos y pescadores de la isla; "Gloeden recreó, a la medida de sus sueños, una Grecia que nunca había existido y que celebraba la eterna juventud y la belleza de los efebos" (Belmonte, 2015, 67). Del mismo modo, las pinturas de Henry Scott Tuke (1858-1929) muestran la "amistad" de jóvenes desnudos que se observan entre sí mientras toman un baño en el mar, se visten o se desvisten o se reclinan para descansar sobre la hierba. Con mucho acierto Alberto Mira concentra en un sintagma esta operación de disimulo y ambigüedad, pasando de la tradición judeo-cristiana a la helénica y del concepto de 'pecado' al concepto de 'belleza': “la Sodoma sublimada” (Mira, 2007, 100).

\section{Novelas, debates y representaciones de la homosexualidad en la España de principios de siglo}

La ola homofílica que recorrió el continente europeo de manos del helenismo cuajó, pues, en España con visos muy particulares. En primer lugar, no existió una figura literaria fuera de los géneros populares que portara el estandarte de la disidencia sexual, como sí ocurrió -no sin problemas- en el caso francés, alemán, inglés o norteamericano; habrá que esperar a la poesía de Federico García Lorca y a la de Luis Cernuda para que la condición gay, aunque mínimamente, sea tomada en consideración por el "alto" mundo cultural; tampoco lo será la figura de Jacinto Benavente, aun con sus poesías homoeróticas a los efebos o marineros (tema recurrentemente ligado a lo gay: cfr. Izzi Orts, de Edward Burra, 1937; cfr. Querelle, de Rainer Werner Fassbinder, 1982) o el galardón del Premio Nobel en 1922, que recibió expresamente por su actividad teatral. En segundo lugar, si bien fueron leídos los autores de referencia antes mencionados, las creaciones españolas de principios de siglo fueron de carácter popular, masivo, muchas veces por entregas, con todas las características que llevan asociadas este tipo de soportes: personajes estereotipados, conflictos 
manidos, exceso de sentimentalidad, giros inesperados, exploración de las bajas pasiones, etc... y todos los controles por parte de la censura y la moralidad públicas. En tercer lugar, las estéticas en que se plasmaron las primeras representaciones de la homosexualidad moderna se movieron entre tradiciones muy distintas: por un lado, se nutrieron de los últimos coletazos de la escuela naturalista, que estudiaba los aspectos y efectos más controvertidos de las sociedades modernas, entre ellos la prostitución; por otro lado, se entregaron sin frenos al modernismo y al decadentismo, que permitían la recreación de la belleza de lo prohibido, lo decadente y en cierto modo lo inmoral, sancionando las ficciones incluso con prólogos o notas moralizantes.

Luis Antonio de Villena (1992) destaca la maestría y padrinazgo del escritor Felipe Trigo (1965-1916) en todo este tipo de producciones eróticas y distingue, a continuación, dos generaciones posteriores: la primera, bajo el dominio de Antonio de Hoyos y Vinent y el influjo del simbolismo y decadentismo de filiación modernista, con el gusto por la transgresión, la perversión, la prevalencia del Mal sobre el Bien y los atentados contra la moral burguesa, y que abarcaría las dos primeras décadas del siglo XX (1900-1920); la segunda, bajo la influencia de Álvaro Retana, que comenzaría precisamente tras la Gran Guerra, en consonancia con la belle époque, la gran fiesta europea que intenta superar los traumas de la contienda bélica en todo el continente, subvirtiendo la escala de valores victoriana y tradicionalista, y entregándose de lleno a las nuevas formas de vida modernas: nuevos bailes y nueva música, nueva moda en el vestir, carreras de coches, competiciones deportivas, salas de casinos, salas de fiesta, restaurantes, cabarets, cuplés, music-halls, etc. Álvaro Retana, como veremos, será el representante de la frivolidad, el cinismo, la perversión sexual y la galantería precisamente hasta 1927 (Villena, 1992, 322), momento en que comienza el declive de la literatura galante.

Aceptando la división cronológica que propone Luis Antonio de Villena, es interesante la aportación Alberto Mira (2007, 
24-26), quien distingue tres posiciones frente a la cultura gay de este principio de siglo: el malditismo, ligado al decadentismo, de origen francés, que pretende subvertir los valores del bien y del mal, cuyo representante sería precisamente Antonio de Hoyos y Vinent; la homofilia, de origen alemán, que pretende iniciar un discurso de normalización de las sexualidades no heterosexuales, donde encontraríamos a Alberto Nin Frías o Pedro Badanelli; y la estética camp, considerada frívola, superficial, ruidosa, no necesariamente politizada pero que en la práctica "contribuye a desestabilizar el discurso hegemónico dando voz al homosexual" (Mira, 2007, 26), cuyo máximo exponente será Álvaro de Retana.

En 1933, el uruguayo Alberto Nin Frías publicó en Madrid (Morata) un estudio titulado El homosexualismo creador. Un año antes, el diplomático montevideano había sacado a la luz Alexis o el significado del temperamento homosexual (Madrid: Morata, 1932), y mucho antes obras reflexivas sobre la fe, el cristianismo, la historiografía o la crítica literaria, además de las novelas Sordello Andreas (1912) y Marcos, amador de la belleza (1913) en Valencia (Editorial F. Sempere y compañía). La tesis de El homosexualismo creador es inequívoca:

La inclinación de la libido hacia el propio sexo, [sic] se halla cabalmente entre estos sentires vergonzantes que, hoy mejor informados que en otras épocas de criterio simplista, visto a la luz de la psicología, no es necesariamente un vicio, una perversidad o una cosa mórbida, sino antes bien, una búsqueda de la voluptuosidad, cuando otros medios han fallado al organismo. El hombre está mentalmente constituido para la persecución de la satisfacción máxima del organismo y debemos admitir que no todos están conformados para encontrarla de la misma manera. [...] La utilidad de este sentir o su finalidad dentro del cuadro general de la Naturaleza, son arcanos de Dios, y será difícil dilucidarlos mientras la sociedad no dé plena carta de ciudadanía al ser urano para desenvolver su vida libremente. (Nin Frías, 1933, 11) 
Nin Frías elaborará todo un tratado para demostrar la "normalidad" de la naturaleza homosexual, pero también su carácter extraordinario. Apelando a los avances científicos, reclama una sociedad abierta que dé "carta de ciudadanía" al homosexual, es decir, que destierre los delitos de indecencia y sodomía del código penal y que contribuya a valorizar este fenómeno "natural". Con suma voluntad científica, elabora una clasificación de tipos de hombres y mujeres homosexuales, dependiendo de su virilidad o afeminamiento en cada caso ${ }^{12}$ (Nin Frías, 1933, 22-24). Pero lo más interesante del tratado es el recorrido por la historia universal en 56 capítulos, destacando a aquellos hombres homosexuales que marcaron el signo de los tiempos, para demostrar "la concomitancia del uranismo con toda suerte de virtudes y talentos" (Nin Frías, 1933, 11). Es significativa la ubicación del origen de la homosexualidad en la tradición judía (frente a la destrucción de Sodoma, rescata la "amistad" entre Jonatán y David, o al hijo de Saúl), junto a la tradición helénica y romana (los diálogos y obras que tratan de la amistad entre hombres, las obras artísticas homoeróticas o efebofílicas, el comportamiento urano de Hadriano [sic]) o la cristiana (los primeros años del cristianismo, San Agustín y otros padres de la Iglesia, San Francisco). En su intento de iluminar la "normalidad" homoafectiva, Nin Frías explora la tradición bíblica, el mundo clásico antiguo, las tribus primitivas de África, Asia, Pacífico, India, Persia, Turquía, Japón, el mundo árabe, y dedica largas páginas a los reyes de Castilla, a los reyes de Inglaterra, al renacimiento italiano y francés, a la Inglaterra y a la Francia del siglo XIX, y a personalidades como Lord Byron, Shelley, Keats, Lord A. Tennyson, Fitz Gerald, Walt Whitman, Emerson y H. D. Thoreau, el cardenal J. E. Newman, Diderot, Verlaine y, por sobre todos ellos, Oscar Wilde, a cuya vida y a cuya obra literaria (con especial mención a El retrato de Dorian Gray) dedicará 5 capítulos, considerándolo "el mártir

12 Lo que en la actualidad clasificaríamos como activo o pasivo, en el caso del hombre, o femenina o masculina, en el caso de la mujer. 
del uranismo moderno" (Nin Frías, 1933, 109). La conclusión a la que llega Alberto Nin Frías es contundente:

La uranidad no resta al ser humano -toda proporción guardada de dignidad y decencia- la maestría, ni la habilidad, la virtud mística ni la profana, antes bien suele sublimar todas estas excelencias de la humana criatura. [...]

Hidalgo es, al fin y a la postre, aquel que como hidalgo se conduce, independientemente del curso de su sed de amar; mas la actual sociabilidad aún está poco preparada para entenderlo de esta suerte. (Nin Frías, 1933, 368)

Es significativo que el uruguayo Nin Frías publique su tratado normalizador en Madrid y bajo el aperturismo de la Segunda República (Cleminson, Vázquez García, 2007, 1). No por casualidad, en la España que se abría a la Modernidad, coincidirían pensadores y escritores de ambos lados del Atlántico que se unirían a la "moda" del erotismo y de la homosexualidad con novelas populares: ya el cubano Eduardo Zamacois o el español Ramón Pérez de Ayala habían explorado el tema tangencialmente y lo habían juzgado con suma rigidez; el marqués de Hoyos y Vinent se había recreado en el catálogo de vicios placenteros de la sexualidad disidente desde la estética decadentista de principios de siglo; sin embargo, las ficciones de los años veinte serían mucho más explícitas y desbordarían los márgenes del género erótico. En 1924 el escritor y diplomático chileno Augusto D'Halmar publicó en España Pasión y muerte del cura Deusto (1924), y en 1927 el hispano-cubano Alfonso Hernández-Catá, también diplomático y escritor, publicó $E l$ ángel de Sodoma (1927). En ambas ficciones los protagonistas (respectivamente: el sacerdote Ignacio Deusto, quien destinado a la parroquia de San Juan de la Palma en Sevilla se enamorará de un adolescente gitano llamado Pedro Miguel, y José-María, quien se da cuenta de su atracción por los hombres, aunque nunca llega a cumplir su propósito) logran asumir y aceptar su homosexualidad, aunque se niegan la posibilidad 
de mantener contacto sexual o afectivo con otro hombre (incluso cuando es correspondido, en el caso del cura Deusto). Ambos finales son trágicos: el suicidio de los protagonistas. Se pueden leer ambas novelas como el destino trágico de aquellos que no encajan en los cánones heteronormativos, pero también como una acusación a la homofobia institucionalizada en la sociedad española (y no solo española, evidentemente, dado el origen de los autores). No obstante, la novela de Hernández-Catá, El ángel de Sodoma, va acompañada de prólogo y epílogo de Gregorio Marañón y del abogado Luis Jiménez de Asúa, respectivamente, en los que se insiste en el carácter patológico de la homosexualidad, aun alejándolo de la consideración de vicio, pecado o delito, reinsertándola en el discurso médico para protegerla del discurso jurídico y legal.

Con un final trágico se presenta también Serenata del amor triunfante (1929), del gaditano Pedro Badanelli (recuperado recientemente por la profesora Noël Valis, 2016). Este escritor se exiliará en Argentina, será ordenado sacerdote y será desde los años cuarenta un ferviente peronista (Valis, 2016, 7), bajo cuya protección morirá precisamente su amigo Alberto Nin Frías. En la Serenata, el conflicto se desarrolla entre dos hermanos, Juan e Irene, enamorados a la vez del mismo hombre, Pepiño, un marinero que entra a servir a la casa familiar. La defensa del amor que realiza Badanelli va desde lo más genérico:

Es necesario amar. La vida es triste, infinitamente triste. Se está solo, muy solo, y llega la noche y no se tiene a nadie a quien decir una palabra. Es necesario amar, cada uno del modo que pueda, de cualquier manera, porque todos los amores son igualmente bellos. (Badanelli, 2016, 176)

hasta lo más concreto, pues estas son las reflexiones que Irene encuentra en el reverso de una fotografía del marinero que guarda su hermano Juan bajo secreto: 
Todo amor, en general, no es ni bello ni digno de encomio, sino únicamente el que nos incita a amar bellamente. [...] Mientras son jóvenes aman a los hombres, disfrutan durmiendo con ellos y en estar entre sus brazos y son los primeros entre los adolescentes y los adultos, como si fueran de una naturaleza mucho más viril. Sin ninguna razón se los acusa de no tener pudor por lo que proceden así; es porque poseen un alma esforzada y valor y carácter viriles por lo que buscan a sus semejantes, y la prueba es que con la edad se muestran más aptos para el servicio del Estado que los otros. (Badanelli, 2016, 211)

El desenlace, como he avisado, es trágico: los celos se apoderan de Irene, quien se entrará a escondidas una noche en el dormitorio del marinero, le obligará a confesar su (ambiguo) amor por Juan y le prometerá entregarse a él para disfrutar los placeres de la carne; en pleno acto sexual, le propondrá drogarse con morfina para multiplicar el placer, pero la jeringa que prepara Irene no será de morfina sino de cianuro potásico.

La obra de Pedro Badanelli, con una estética decadentista y con una evidente marca helenista (en la descripción del cuerpo desnudo de Pepe, en las reflexiones del narrador sobre el amor platónico), retoma algunas de las ideas de su amigo Alberto Nin Frías: el amor decente de los homosexuales, y su reafirmación en la condición viril que les hace sumar virtudes. Y recrea también, aunque mínimamente, la modernidad de los años veinte: los transatlánticos que hacen la ruta Cádiz-Buenos Aires, la independencia de las mujeres, los teatros y los cines de terraza, los veraneos en casas magníficas de la costa malagueña, el expreso que conecta las capitales de España, las fiestas de la jet-set en la villa de veraneo, "el baile y el flirteo", los navíos de bandera francesa, inglesa, italiana y alemana, atracados con motivo de una fiesta extraordinaria, los "cock-tails" y cenas de gala en el barco, los invitados a la fiesta ofrecida por el Almirante de la escuadra italiana y que llegan de todas partes, veraneantes de todas las regiones de España, los marinos extranjeros, los vestidos de gala, el 
amor disimulado entre mujeres o la presencia de homosexuales o las lecturas europeas para la joven aristocracia, pues Juan está leyendo L'ersatz d'amour, una novela francesa publicada en 1923 por Willy y Ménalkas de carácter homoerótico, los viajes a París o Italia, el uso lúdico de las drogas:

Espera -le dijo-, es necesario que lleguemos esta noche al paroxismo del placer. Espera, vamos a ponernos una inyección de morfina; ¿no has saboreado nunca los efectos de la morfina? (2016, 258).

Badanelli recrea la atmósfera moderna de la juventud acomodada y urbana de los años noventa. En este ámbito, es posible poner en relación la Modernidad, la apertura al mundo, la relajación de costumbres y la entrega al hedonismo, con la normalidad del amor homosexual. El caso del gaditano es de los pocos en el que el autor no se aparta de los significados de sus ficciones, y plantea en texto y paratextos la aceptación de la homosexualidad como un asunto elevado, concomitante con la belleza y el amor.

Pero su posición no será la generalizada. La mayoría de las obras en que se visibiliza un amor disidente, contienen además textos o paratextos con voluntad moralizadora. Asistimos, en mi opinión, a una paradoja, fruto del momento histórico en que se publican estas obras: existe una voluntad de visibilizar el amor homosexual, pero pocos se atreven a cruzar la línea de la "normalidad" social y a considerarlo, con todas sus consecuencias, fruto de una Modernidad saludable para la nueva sociedad. A la homofobia imperante, debemos sumar la dictadura de Primo de Rivera (1923-1930) y su política censora, pero junto a ella también los aires modernos de la belle époque, los avances tecnológicos (coches, metros, teléfonos...), el nuevo estilo de vida urbano, la moda, la música, las drogas, las ruletas de casino, los cabarets, los espectáculos de transformismo... que imprimieron un aire de fiesta en el periodo de entreguerras. Un aire de fiesta matizado: no por casualidad prácticamente todos los escritores 
que se inmiscuyen en fabulaciones homoeróticas pertenecen a clases acomodadas (burguesía o incluso aristocracia), viven en un ambiente distinguido y están avalados por el cosmopolitismo con que conducen sus vidas.

Será frecuente entonces que el límite de la Modernidad, tal y como veíamos en Alberto Mira, lo marque la homosexualidad. Como decíamos, si bien existe una significativa producción dedicada a la visibilización homosexual, muchos de los escritores que hablan de ella acompañarán sus obras con prólogos, notas, epílogos o distintos paratextos atenuando las afirmaciones de los personajes o distanciándose de los juicios benevolentes que se pueden inferir de las novelas. Tal es el caso de Álvaro Retana, el más lúdico de todos los eróticos (Villena, 1992; Heuer, 2000; Ezpeleta Aguilar, 2006; Zamostny, 2009), quien dará títulos extraordinarios como Las locas de postín (1919), Los extravíos de Tony (1919), El príncipe que quiso ser princesa (1920), El encanto de la cama redonda (1922), Mi novia y mi novio (1923) o El infierno de la voluptuosidad (1924), y que a pesar de lo explícito y celebratorio de sus títulos pondrá distancia (una distancia, podríamos pensar, fingida, estratégicamente explícita para evitarse problemas con la justicia -pues fue arrestado en un par de ocasiones- [Villena, 1999]) con respecto a su imaginación:

No comparto, ni siquiera simpatizo, con ninguna de las ideas sustentadas por los personajes de mis novelas. Yo soy un pintor de ambientes que procura describir exactamente cuanto juzga interesante para el público; pero no le reconozco a nadie el derecho de pensar que yo disculpo cuanto pasa en las páginas de mis obras. [...] Como un doctor en su laboratorio estudia en los conejos de Indias los más enrevesados problemas vitales, yo he estudiado en las almas de los más grandes pervertidos complicaciones psicológicas y si se quiere patológicas, dignas de ser expuestas a la voracidad de los lectores con una finalidad muy moral: para que los viciosos se avergüencen de sí mismos y los puros no lo imiten. (Retana, prólogo a El veneno de la aventura, 1924; en Cruz Casado, 1996, 40) 
O bien:

Siempre que pude me declaré escritor intrascendente, profesional de la frivolidad literaria que orientaba sus producciones en un sentido atrevido y moderno, sin otro propósito que el de pintar fielmente las malas costumbres de mi tiempo, como hay doctores que se lanzan a estudiar el cáncer o la lepra. [...] Me veo precisado a insistir en lo tanto que repetí siempre. Esto es: que no apruebo ni comparto ninguna de las ideas y conductas de los personajes que circulan por mis producciones. Me limito a pasear mi espejo de novelista por esos ambientes en que ningún otro escritor español se atrevió a internarse antes que yo. [...] No hay tesoro más valioso que el de nuestra regularidad sexual. (Prólogo a A Sodoma en tren botijo; Retana, 2004, 155-57).

También Pedro Badanelli toma las mismas precauciones de evocaciones stendhalianas en Serenata del amor triunfante (1929): "Retratar la Vida tal y como es, y no tal y como debería ser, ese es el pecado de este libro" (Badanelli, 2016, 71). Tales afirmaciones recuerdan a los argumentos esgrimidos por Émile Zola en defensa del carácter científico del naturalismo en el célebre prólogo a la segunda edición de Thérèse Raquin (1868), o a La cuestión palpitante (1881) de Emilia Pardo Bazán. Pero mientras Badanelli no condena lo representado, Retana se muestra furibundo ante ello.

Álvaro Retana es el máximo representante de la contradicción de entreguerras. Defensor de la frivolidad, escritor de literatura galante, amante de la noche madrileña, escritor de cuplés (cantados incluso por Sara Montiel), biógrafo del primer travesti de España, Egmond de Bries, novelista autodenominado "el más guapo del mundo" (Cruz Casado, 1996; 2001), crítico inmisericorde con sus contemporáneos (La ola verde, 1931, bajo el seudónimo de Carlos Fortuny), diseñador de figurines para revistas de moda y activista de la transgresión y la perversidad (Villena, 1992: 318). Pero al mismo tiempo, el único escritor procesado dos 
veces durante la dictadura de Primo de Rivera y, finalmente, disidente de la libertad de la que hacen gala sus propios personajes.

Las locas de postín (1919) tiene por subtítulo "Novela de malas costumbres aristocráticas". Como es habitual en el autor, abre la ficción una advertencia al lector: la novela pone en escena a "seudohombres", "representantes del tercer sexo" (Retana, 2004, 34), entregados a la inmoralidad y a la bajeza, a la abyección y al desenfreno; y pone distancia con ellos: "yo sería incapaz de cometer el menor pecado ni de transigir con la más leve inmoralidad; pero encuentro muy oportuno que delincan los demás porque sus aventuras equívocas, sus monstruosas aberraciones y sus fantásticas incongruencias, me sirven a mí, luego, de elemento para confeccionar unas novelas que, desgraciadamente, se venden como pan bendito" (Retana, 2004, 31-32). Llama al lector a gozar de la historia y a abominar del tercer sexo (Retana, 2004, 36), y no sé si sería más justo pensar que tal furibundo prólogo supondría una estrategia de ambigüedad autorial, pues lo celebratorio de los personajes, de los diálogos, el desenfado en las descripciones y los chistes, contrastan con el autoritarismo moral que exhibe en estas notas. No podemos excluir, pues, la ventaja de la ironía y el cinismo.

La historia de la novela es simple: el joven aristócrata Rafaelito Hinojosa de Cebreros recibe en su majestuosa casa a su amigo Manolo Castilla, otro joven apuesto aunque cleptómano. Ambos son afeminados, aficionados a la moda a la inglesa, a los maquillajes y a los peinados, a las veladas entre amigos y a los manjares exquisitos. Manolo Castilla se ha enterado de que el amante de Rafaelito, el marqués de Villamalo, le ha dejado 4.000 pesetas antes de irse de viaje, y su propósito será gastarlas juntos o, en un descuido, robárselas. Por esa razón, le propone conocer a un apuesto joven argentino que, según dice Manolo, le ha preguntado por Rafaelito, pero entre la treta y la intervención del hermano de Rafael, este se quedará sin dinero y sin argentino.

El desenfado con que escribe Álvaro Retana la vida madrileña nos hace dudar de los propósitos de su prólogo. Los dos 
amigos salen de casa para almorzar en el hotel Ritz con los labios pintados, la cara llena de polvos, con un "traje tailleur azul porcelana", manteleta de pieles y chapines, extrañados de que los niños les insulten a su paso: “زEs que no puede ser! Estos hombres de pueblo, cuando ven a las damas del gran mundo se sienten bolcheviquis [sic]. ¡Somos demasiado jóvenes y hermosas para pasar inadvertidas!" (Retana, 2004, 58). A su vuelta, Rafaelito ensayará con su gramófono los pasos de baile del Tabaquiño, ataviado con una bata de su madre, mientras espera paciente al argentino. La llegada de otro amigo, Luis Morán, da pie a conocer nuevos detalles de la cultura gay madrileña: aficionados a los cuplés, al flamenco y a los toros, a las "tartas, sándwichs y bombones" de Tournié (fonda de la calle Mayor), a los cotilleos sobre amores y desamores de sus amigos, a las aventuras con nuevos amantes (incluso pagando; Retana, 2004, 76), y a los que reciben completamente desnudos cubiertos únicamente con un mantón de Manila. El tropiezo de Manolo Castilla con otro amigo, Paquito Alfayate, nos ofrece más información sobre esa subcultura de entreguerras:

-Por cierto, a mi vuelta a la corte me he enterado del amable rasgo que ha tenido el Ayuntamiento contigo. ¡Qué atención! ¡Ponerte un urinario en la misma puerta de tu casa! ¡Estarás contentísimo...! -¡Ay, no me hables de esas cosas! -suplicó Alfayate-. Desde que conocí al príncipe, no puedes darte idea de lo seria que estoy. (Retana, 2004, 106)

Esta alegre conversación nos testimonia que, ya a principios de siglo, los urinarios públicos instalados por la villa de Madrid se habían convertido en lugares de encuentro sexual furtivo, espacios de permisividad y de discreción donde establecer contactos entre varones y donde satisfacer el deseo sexual rápidamente. Los urinarios públicos fueron una solución encontrada por José Osorio y Silva, alcalde de Madrid entre 1856 y 1865, como medida higiénica que evitara la suciedad y los malos olores en la ca- 
pital. Los encuentros sexuales, que ya se producían en jardines y parques (Huard, 2014, 109), se trasladarán también a las "tazas", a los cines, al metro, a los centros comerciales y a otros lugares públicos. El Código Penal castigaba como "escándalo público" estas actuaciones, de modo que estos espacios se convirtieron pronto en objetivo de la policía, pero también de prostitutos, por un lado, y de ladrones y delincuentes, por otro, pues las víctimas declinarían denunciar los robos, chantajes, agresiones físicas o extorsiones al estar "delinquiendo", a su vez, y sobre todo por miedo a que su homosexualidad se hiciera pública ${ }^{13}$. Contrasta, pues, el peligro que entrañaba el sexo público con la animada conversación entre Manolo Castilla y Paquito Alfayate, quienes celebran la colocación de un urinario a la puerta de casa ${ }^{14}$.

Pero, además, ambos amigos deciden entrar en un "bar" (neologismo aparecido en la primera década del siglo ${ }^{15}$ ) donde hay un camarero suizo muy atractivo, y emplazarse para ir a ver el espectáculo de Egmont de Bries al teatro Price:

13 En Huard, Geoffroy (2014). Los antisociales. Historia de la homosexualidad en Barcelona y París, 1945-1975, encontramos un capítulo dedicado a los lugares y prácticas homosexuales en el espacio público, así como sus peligros y la represión que desataron. Cfr. Pp. 109-148.

14 Otra de las "bondades" de los urinarios públicos era que desplazaban los encuentros sexuales de la casa a la calle, de modo que el homosexual protegía su domicilio y su identidad, integrándose en el anonimato urbano. Así pues, el contraste con el texto de Retana es todavía mayor.

15 El Corpus Diacrónico del Español recoge como primeras acepciones de la palabra "bar" una crónica de Nedoc titulada "Ecos de París" publicada el 1 de septiembre de 1878 en El Campo, en la que describe el ambiente nocturno de los cabarets de Folies Bergère comparándolos con los bares de Londres. La segunda entrada es de Benito Pérez Galdós en Fortunata y Jacinta (1886-87), en el que se alude a la vida londinense: “iQué silencio tan solemne hay ahora! El chorrear de la fuente de Pontejos, es lo que se siente siempre, y alguno que otro coche que pasa por la Puerta del Sol... Son los trasnochadores, que se retiran. Así iba yo en mi cab al salir del club de Picadilly... solo que mi cab corría como una exhalación y estos carruajes andan poco y parece que se deshacen sobre los adoquines. ¡Y cómo se me refrescan las memorias...! Parece que estoy mirando a aquella prójima que se me apareció una noche en Haymarket, al salir de aquel bar... ¡No me ha ocurrido otra...! ¡Y cómo se parecía a esta tonta de Aurora Fenelón!". 
La clase de trabajo artístico de Egmont de Bries, el celebrado y popular imitador de estrellas varietinescas, es la más a propósito para entusiasmar a los representantes del sexo indeciso, por lo que hay en ella de ambiguo y provocador. Un hombre suplantando la cualidad femenina ante las majestuosas barbas de la opinión pública, sería inadmisible; pero amparándose en el sagrado pabellón del arte, como Egmont de Bries, lejos de provocar un movimiento de protesta, conquista la voluntad del público y obtiene, como premio a su labor equívoca, el general aplauso. (Retana, 2004, 111-112)

El travestismo del artista, como pretende el narrador, queda disculpado por el arte con el que actúa; la misma tabla de salvación que reclama el autor con su novela porque, aun hablando de "monstruosas aberraciones", lo hace en pro del arte. A continuación, el narrador nos detalla qué tipos de "locas" existen en la sociedad madrileña y acuden al cabaret de Egmont de Bries:

Locas por convicción, como Sarabia, el modisto aristocrático, que ha convertido en señoritos a tantos organilleros; locas profesionales, como Paquito Alfayate; locas en entredicho, como Javier Algaida, que, a pesar de sus dos bodas, continúa siendo tan sospechoso como antes de casarse; locas escandalosas, como Pepito Rocamora, el joven dibujante de elegancias femeninas y su inseparable camarada de correrías, Aurelio de Regoyos, novelista aristocrático de fama universal; locas vergonzantes, como la Lopo, la Mazona o la Alberico; locas románticas, como la Pérez de Acevedo, la Salvi o Mari-Pepa Andrés; locas contemplativas, como Juliana Garamendi, y locas vetustas, como Paca la Traviesa, la Noeli o la Alfalfa, sin contar con esas locas en germen, que están deseando que las [sic] pongan un pie delante para dar el primer tropiezo, y el inevitable grupo de anfibios, partidarios de repicar y andar en la procesión. (Retana, 2004, 113)

La escena, pintada de manera coloquial y desenfadada, dista mucho de parecer una condena como nos había advertido el 
autor en su prólogo. Al contrario, parece una celebración de esa subcultura gay que encuentra en la vida urbana, por fin, espacios de visibilidad y de relación entre homosexuales, referentes artísticos y lugares de permisividad donde combatir o contrarrestar la institucionalización y extensión de la homofobia.

\section{Conclusiones. Sentido de lo moderno}

Cuando Federico García Lorca escribió Poeta en Nueva York (1929-30), incluyó su famoso poema "Oda a Walt Whitman". En él rendía homenaje a una de las figuras más reconocibles de esa naciente cultura gay, el "viejo hermoso Walt Whitman" en medio de una "Nueva York de cieno, / Nueva York de alambres y de muerte". El viejo poeta se convertía en referente para los homosexuales, que viven su disidencia sexual entre la luminosidad y la violencia:
[...] Y se despeñan
sobre tu barba luminosa y casta,
rubios del norte, negros de la arena,
muchedumbres de gritos y ademanes,
como gatos y como las serpientes,
los maricas, Walt Whitman, los maricas
turbios de lágrimas, carne para fusta,
bota o mordisco de los domadores. [...]

Lorca no esconde el dolor de las "heridas" o los sinsabores del amor prohibido ("leve sabor de gasolina"), y recrea ese mundo furtivo de los puertos y los puentes en los que juegan los muchachos. Pero en su canto establece un límite para su solidaridad con los homosexuales: mientras sentirá pesar y conmiseración por los niños y su despertar sexual, por los hombres de doble vida, por la condición sufriente del homosexual, condenará a aquellos que se entregan al placer y a la diversión. Son famosos los versos que siguen: 
Por eso no levanto mi voz, viejo Walt Whitman, contra el niño que escribe nombre de niña en su almohada, ni contra el muchacho que se viste de novia en la oscuridad del ropero, ni contra los solitarios de los casinos que beben con asco el agua de la prostitución, ni contra los hombres de mirada verde que aman al hombre y queman sus labios en silencio. Pero sí contra vosotros, maricas de las ciudades, de carne tumefacta y pensamiento inmundo, madres de lodo, arpías, enemigos sin sueño del Amor que reparte coronas de alegría.

Contra vosotros siempre, que dais a los muchachos gotas de sucia muerte con amargo veneno.

Contra vosotros siempre, Faeries de Norteamérica, Pájaros de la Habana, Jotos de Méjico, Sarasas de Cádiz, Ápios de Sevilla, Cancos de Madrid, Floras de Alicante, Adelaidas de Portugal.

¡Maricas de todo el mundo, asesinos de palomas!

Esclavos de la mujer, perras de sus tocadores, abiertos en las plazas con fiebre de abanico o emboscadas en yertos paisajes de cicuta.

¡No haya cuartel! La muerte mana de vuestros ojos y agrupa flores grises en la orilla del cieno. ¡No haya cuartel! ¡Alerta! 
Que los confundidos, los puros,

los clásicos, los señalados, los suplicantes

os cierren las puertas de la bacanal.

No es descabellado pensar que esos cancos de Madrid, esos asesinos de palomas, esas maricas de las ciudades, remiten a las producciones galantes de Álvaro Retana y sus contemporáneos. Por lo tanto, el alegato de Federico García Lorca estaría dirigido contra toda esa representación frívola de la homosexualidad. En este sentido, Luis Cernuda se encuentra muy cercano a Federico García Lorca. En 1931 publicaría Los placeres prohibidos, en el que encontraremos alusiones veladas (o no tan veladas) al amor homosexual. Tomo como ejemplo el texto más representativo del poemario:

Si el hombre pudiera decir lo que ama,

Si el hombre pudiera levantar su amor por el cielo

Como una nube en la luz;

Si como muros que se derrumban,

Para saludar la verdad erguida en medio,

Pudiera derrumbar su cuerpo, dejando solo la verdad de su amor,

La verdad de sí mismo,

Que no se llama gloria, fortuna o ambición,

Sino amor o deseo,

Yo sería aquel que imaginaba;

Aquel que con su lengua, sus ojos y sus manos

Proclama ante los hombres la verdad ignorada,

La verdad de su amor verdadero.

Aunque en términos estéticos, Lorca y Cernuda se adhieran en estos dos poemarios a las estéticas vanguardistas, y en concreto al surrealismo, no dejan de proclamar la intimidad del yo poético, y recluyen (de nuevo) la homosexualidad en la esfera de lo privado, de lo íntimo y de lo indecible. Es innegable su mo- 
dernidad literaria, pero resulta cuanto menos contradictoria la tematización de la homosexualidad, por un lado, y, por otro, su defensa del carácter íntimo, doloroso y subjetivo, su reclusión en definitiva en el armario.

Mucho menos avanzados en su estética, Nin Frías, Badanelli o Retama, suponen, por el contrario, una defensa de la homosexualidad pública (si bien es cierto que con grandes reservas, ambigüedades y contradicciones), una celebración de los nuevos tiempos, un goce de la vida urbana, de las nuevas costumbres relajadas y hedonistas, de los nuevos productos de consumo y los nuevos lugares de moda, del humor que los acerca a "la otra generación del 27". A través de los escritores de las primeras décadas de los años treinta, podemos rastrear la naciente cultura gay en las ciudades europeas, las nuevas relaciones entre hombres, las nuevas prácticas sociales, el ocio y el entretenimiento de esta subcultura, que se alió con la Modernidad para su eclosión y desarrollo. Pero a la vez, la homosexualidad marcó el límite de la tolerancia de una sociedad que estaba redefiniendo los conceptos de "libertad" e "igualdad", y que lamentablemente aún habría de asistir al auge del fascismo y de la dictadura de Franco durante cuarenta años. El nuevo Estado fascista cercenaría por completo estos anhelos de "libertad" e "igualdad", reinscribiendo al Estado español en un periodo antimoderno durante muchos años, en el que Lorca y Cernuda no tendrían cabida, pero tampoco los galantes, eróticos, sicalípticos o frívolos como Badanelli, exiliado en Argentina; Nin Frías, muerto en 1937; Hoyos y Vinent, apresado por las autoridades franquistas y muerto en la cárcel de Porlier en 1940; o Retana, condenado a muerte y luego a cadena perpetua por intercesión (al parecer) del Papa, depurado de la administración a su salida de la cárcel en 1948, y perdido en una España completamente distinta a los locos años veinte, en la que no había espacio para la frivolidad ni la travesura.

La Modernidad de esta literatura apenas encontró defensores durante su apogeo, aunque estos textos fueron leídos de forma masiva. Tampoco encontró defensores en las décadas sucesivas. 
Solo ahora, al calor de la brillante generación del 27, podemos alumbrar a esta otra generación que entretuvo, visibilizó e intentó ampliar los límites de la normalidad, la igualdad y la libertad en una España que aspiraba a ser moderna.

\section{Bibliografía}

Badanelli, Pedro (2016), Serenata del amor triunfante, ed. Noël Valis, Sevilla, Renacimiento.

Balló, TÀnia (2016), Las sinsombrero. Sin ellas, la historia no está completa, Barcelona, Espasa. Proyecto crossmedia a cargo de Tània Balló, Manuel Jiménez y Serrana Torre. Disponible en: https://www.lassinsombrero.com/

Barea, Joan, Corrius, Jesús, Fernández, David, Hernández, Javier, Sánchez, Jordi y Santacana, Aleix (2001), "L'audiovisual 'porno' espanyol”, Treballs de Comunicació, 16, pp. 54-57.

Barreiro, Javier (2001), Cruces de bohemia: Vidal y Planas, Noel, Retana, Gálvez, Dicenta y Barrantes, Zaragoza, UnaLuna.

Belmonte, María (2015), Peregrinos de la belleza. Viajeros por Italia y Grecia, Barcelona, Acantilado.

Berman, Marshall (2008), Todo lo sólido se desvanece en el aire, Madrid, Siglo XXI.

Cleminson, Richard; Vásquez García, Francisco (2007), Los Invisibles: A History of Male Homosexuality in Spain, 1850-1940, Cardiff, University of Wales Press.

Cruz Casado, Antonio (1996), “Frivolidad y erotismo. Álvaro Retana, 'el novelista más guapo del mundo'", en Los territorios literarios de la Historia del Placer. I Coloquio de Erótica Hispana, J. A. Cerezo et al. (eds.), Madrid, Huerga \& Fierro, pp. 35-48.

Cruz Casado, Antonio (2001), "Álvaro Retana, 'El novelista más guapo del mundo': erotismo, frivolidad y moda", en Andalucía y la bohemia literaria, M. Galeote (ed.), Málaga, Arguval, pp. 17-48.

Ezpeleta Aguilar, Fermín (2006), "Los extravíos de Tony (1919) de Álvaro Retana", en Hesperia: Anuario de filología hispánica, 9, pp. 39-56. 
Fortuny, Carlos (2015), La ola verde. Crítica frívola, Madrid, Asociación de libreros de lance de Madrid.

García de la Concha, Víctor (1998), Antología comentada de la Generación del 27, Barcelona, Austral.

García Martínez, María Montserrat (2012), La novela de hoy (1922-1932): su público y mercado, Tesis doctoral, Universidad Complutense de Madrid.

Guereña, JEAN-Louis (2000), “La producción erótica española en los siglos XIX y XX", en Actas del XIII Congreso de la Asociación Internacional de Hispanistas, 2, pp. 195-202.

Guereña, Jean-Louis (2012), “Un infierno español. Hacia una bibliografía de las publicaciones eróticas españolas (siglos XIXXX). Problemas y realizaciones", en Analecta Malacitana, 32, pp. 483-516.

Heuer, Jacqueline. (2000), "Álvaro Retana recuperado", en Actas del XIII Congreso de la Asociación Internacional de Hispanistas, vol. 2, pp. 643-654.

Huard, Geoffroy (2014), Los antisociales. Historia de la homosexualidad en Barcelona y París, 1945-1975, Madrid, Marcial Pons.

Huertas Vázquez, Eduardo L. (2015), “Álvaro Retana. Entre el arte frívolo, la novela erótica y la vida libertina", en Fortuny, Carlos (2015), La ola verde. Crítica frívola, Madrid, Asociación de libreros de lance de Madrid.

Insúa, Alberto (2003), Memorias, ed. Santiago Fortuño Llorens, Madrid, Fundación Santander Central Hispano.

López Rubio, José (2003), La otra generación del 27. Discursos y cartas, Madrid, Centro de documentación teatral.

López Ruiz, José María (2001), Los pecados de la carne: crónica de las publicaciones eróticas españolas, Madrid, Temas de hoy.

Mira, Alberto (2007), De Sodoma a Chueca. Una historia cultural de la homosexualidad en España en el siglo XX, Barcelona, Egales.

Nin Frías, Alberto (1933), Homosexualismo creador, Madrid, Javier Morata.

Retana, Álvaro (2004), Las locas de postín. A Sodoma en tren botijo, Madrid, Odisea editorial. 
Romera Castillo, José Nicolás (1995), “Perfiles autobiográficos de la 'otra Generación del 27' (la del humor)", en Actas del XII Congreso de la Asociación Internacional de Hispanistas, 4, pp. 241-247.

Vázquez García, Francisco (2001), “El discurso médico y la invención del homosexual (España 1840-1915)", en Asclepio: Revista de historia de la medicina y de la ciencia, 53, 2, pp. 143-161.

Villena, Luis Antonio de (1992), “Álvaro Retana en el abanico de la novela galante-decadente", en Epos: Revista de filología, 8, pp. 317-328.

Villena, Luis Antonio de (1999), El ángel de la frivolidad y su máscara oscura: Vida, literatura y tiempo de Alvaro Retana, València, Pre-Textos.

Zamostny, Jefrerey (2009), “¡Todos a bordo!: viajes al tercer sexo madrileño en A Sodoma en tren botijo de Álvaro Retana", en Divergencias. Revista de estudios lingüísticos y literarios. Vol. 7, n. 1, pp. 55-60. 